\title{
Characterization and prevalence of spondyloarthritis and peripheral arthritis among patients with inflammatory bowel disease
}

This article was published in the following Dove Press journal:

Clinical and Experimental Gastroenterology

27 September 2017

Number of times this article has been viewed

\author{
Hoda M Malaty ${ }^{1,2}$ \\ Grace Hsiao-Wei Lo'-3 \\ Jason $\mathrm{K} \mathrm{Hou}^{1-3}$ \\ 'Department of Medicine, Baylor \\ College of Medicine, ${ }^{2}$ Michael E \\ DeBakey Veterans Affairs Medical \\ Center, ${ }^{3}$ Center for Innovations in \\ Quality, Effectiveness and Safety, \\ Michael E. DeBakey Veterans Affairs \\ Medical Center, Houston, TX, USA
}

Correspondence: Hoda M Malaty Veterans Affairs Medical Center IIID, 2002 Holcombe Blvd., Houston, TX 77030, USA

Tel +I 7I3 7947280

Fax +17137901040

Email hmalaty@bcm.edu
Background: Joint complaints such as spondyloarthritis and peripheral arthritis are the most common extraintestinal manifestations in patients with inflammatory bowel disease (IBD); however, the evaluation of these symptoms are poorly described.

Objectives: To examine the clinical characteristics and prevalence of ankylosing spondylitis (AS) and other joint complaints among patients with IBD.

Methods: In a local cohort of patients diagnosed with IBD between 1996 and 2009, we performed a retrospective study at the Veterans Affairs Hospital. Patients with IBD were identified by International Classification of Diseases, Ninth Revision codes and confirmed by chart review. The occurrence of AS, peripheral arthritis, and other peripheral and axial joint symptoms were identified.

Results: We identified 626 patients with IBD between ages 18 and 90 ( $90 \%$ males), of whom $57 \%$ had ulcerative colitis (UC), 74\% were Caucasians, and the mean age at diagnosis was 54 $( \pm 16)$ years. Among the study population, 108 patients $(17 \%)$ had at least one type of joint pain. Among these $17 \%$ with joint pain, $12 \%$ had AS, $43 \%$ had peripheral arthritis, $32 \%$ had chronic back pain without AS, and 13\% had other types of joint pain. The overall prevalence of peripheral arthritis among patients with IBD was three times higher than that of AS (7\% vs $2.1 \%$, respectively, OR $3.5 ; 95 \%$ confidence interval [CI] $1.9-6.5 ; p=0.001)$. There was no difference in the prevalence of AS or peripheral arthritis between patients with Crohn's disease and UC. The initial diagnosis of AS occurred after the initial diagnosis of IBD in $80 \%$ of patients within a mean $(\mathrm{SD})$ period of $5.6( \pm 6)$ years.

Conclusion: Spondyloarthritis among patients with IBD is usually diagnosed after the initial diagnosis of IBD. No difference in the prevalence of AS or peripheral arthritis was observed by IBD type, age, or race. Recognition and understanding of these results will have important implications for the management of IBD patients with spondyloarthritis.

Keywords: spondyloarthritis, peripheral arthritis, inflammatory bowel disease, extraintestinal manifestations, Crohn's disease, ulcerative colitis, epidemiology, risk factors

\section{Introduction}

Joint complaints are one of the most common extraintestinal manifestations in patients diagnosed with inflammatory bowel disease (IBD). ${ }^{1}$ Spondyloarthritis is an immunemediated inflammatory disorder that includes ankylosing spondylitis (AS), psoriatic arthritis, juvenile spondyloarthritis, and acute anterior uveitis. ${ }^{1}$ Spondyloarthritis is now classified as axial or peripheral, and is reported to be associated with IBD, ${ }^{1-4}$ with wide variations of the prevalence of both conditions among patients with IBD that range between $5 \%$ and $20 \%$ and $3 \%$ and $25 \%$, respectively. ${ }^{5-7}$ Conflicting results have been reported with regard to the prevalence of spondyloarthritis based on IBD subtype. Studies have reported that there is no major difference in the prevalence of spondyloarthritis 
between ulcerative colitis (UC) and Crohn's disease (CD), ${ }^{8}$ whereas others reported higher prevalence among patients with CD. ${ }^{9}$ Nevertheless, the prevalence of spondyloarthritis in IBD is reported from several cohorts outside the USA, ${ }^{10-14}$ and one study from Olmsted County, Minnesota, estimated that the cumulative incidence of spondyloarthritis among patients with IBD after 10 years was $6.7 \%$ [95\% confidence interval (CI) $2.5 \%-6.7 \%]^{15,16}$

Patients with IBD frequently present with joint complaints; however, the character and means of evaluating these symptoms are poorly described. As these patients with IBD frequently present with axial and peripheral joint pain, we studied the clinical characteristics, prevalence, and incidence of AS, inflammatory peripheral arthritis, and non-inflammatory joint complaints among a cohort of patients with IBD.

\section{Methods}

\section{Materials and methods}

\section{Data source and case identification}

We used data from the local Veterans Affairs (VA) administrative data sets to estimate the prevalence and describe the characteristics of AS and other joint complaints among patients with IBD. The VA Medical SAS datasets contain individual-level data from inpatient and outpatient encounters. VA users with IBD were identified by International Classification of Diseases, Ninth Revision (ICD-9) diagnosis codes for CD (555.x) or UC (556.x) and confirmed to have either CD or UC on chart review, on the basis of available clinical, endoscopic, histologic, or radiologic data. The occurrence of AS, peripheral arthritis, and other joint complaints were identified based on chart review (eg, non-inflammatory back pain and non-inflammatory peripheral arthritis).

A standardized data abstraction form was used to collect information on demographics (eg, age, gender, ethnicity), IBD type, IBD characteristics using the Montreal classification encounters or visits (ie, date, frequency), onset of IBD, onset of AS or joint complaints, diagnosis codes (ICD-9), and medical and surgical procedure codes (Current Procedural and Medical and Surgical Procedure codes/Current Procedural Terminology). Joint complaints were categorized on the basis of clinical documentation as ankylosing spondylitis, non-inflammatory back pain, as well as inflammatory and non-inflammatory peripheral arthritis. Patients with missing data of the elicited variables were excluded from the analysis.

The study was approved by the Institutional Review Board (IRB) of VA Medical Center and Baylor College of Medicine, who deemed written informed consent was not needed due to the retrospective nature of the study.

\section{Statistical analysis}

The prevalence of AS, non-inflammatory back pain, inflammatory PA, and non-inflammatory PA among patients with IBD were calculated over the entire study period (19962009). The numerator was defined as the total number of each condition per year. The denominator was the total number of VA users with IBD per year. The calculated prevalence was standardized for age distribution of underlying populations by applying the direct standardization method using the 1998 VA IBD population.

Moreover, data were independently analyzed for patients with CD and UC. Frequencies of each type of reported joint pain were compared between patients with CD and UC using Fisher's exact tests. The association between potential risk factors (eg, age, IBD subtype, race) and each reported joint condition was analyzed by univariate and multiple regressions analysis.

\section{Results}

Between 1996 and 2009, we identified 626 patients with a confirmed diagnosis of IBD who were eligible for inclusion in the analysis for the current study. Participants were between the ages of 18 and 90; mean (SD) age at diagnosis was 54 $( \pm 16)$ years, $90 \%$ were males, and $57 \%$ were diagnosed with UC. The race distribution was: 74\% Caucasians, 18\% African Americans, 5\% Hispanics, and 3\% others. Among the total IBD study population, 108 patients $(17 \%)$ had at least one type of joint pain. Within the cohort of 108 patients of joint pain, $12 \%$ had AS, $43 \%$ had inflammatory peripheral arthritis, $32 \%$ had non-inflammatory back pain, and $13 \%$ had non-inflammatory peripheral arthritis. The age-specific distribution of the four groups of joint pain was almost similar (Figure 1).

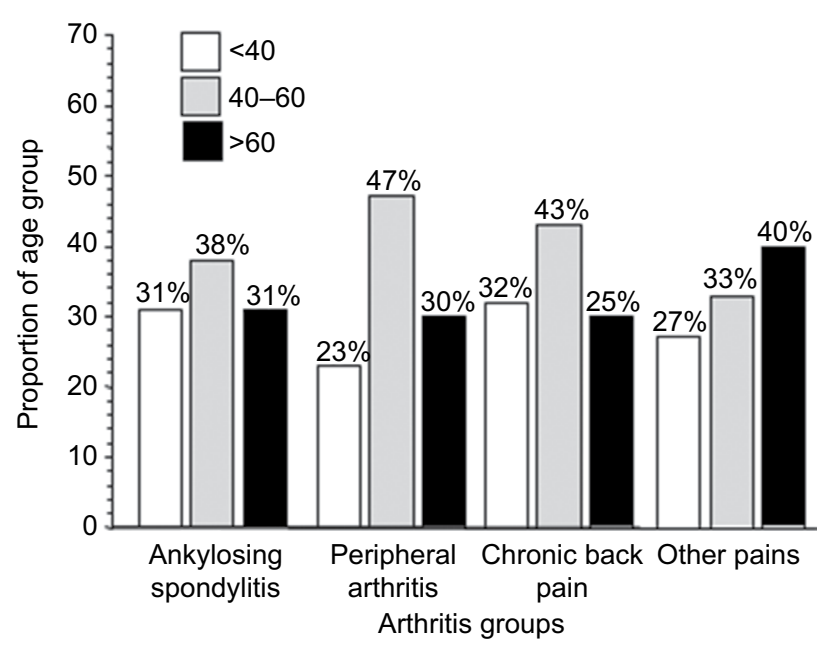

Figure I Age-specific distribution of the four groups of joint pain among the VA cohort in the study population. 
The overall prevalence of inflammatory peripheral arthritis among the IBD study population was three times higher than that of AS ( $7 \%$ vs $2.1 \%$, respectively; OR $3.5 ; 95 \%$ CI $1.9-6.5 ; p=0.001)$. Although the prevalence of AS $(2.1 \%$ and $1.9 \%$, respectively) did not differ between CD and UC patients $(p=0.2)$, the prevalence of inflammatory peripheral arthritis was higher among $C D$ than UC patients ( $8 \%$ vs $6 \%$, respectively); however, the difference did not reach statistical significance level ( $p=0.1$; Figure 2 ). No significant difference was observed in the prevalence of inflammatory peripheral arthritis and AS based on race (Figure 3). Of the 108 patients

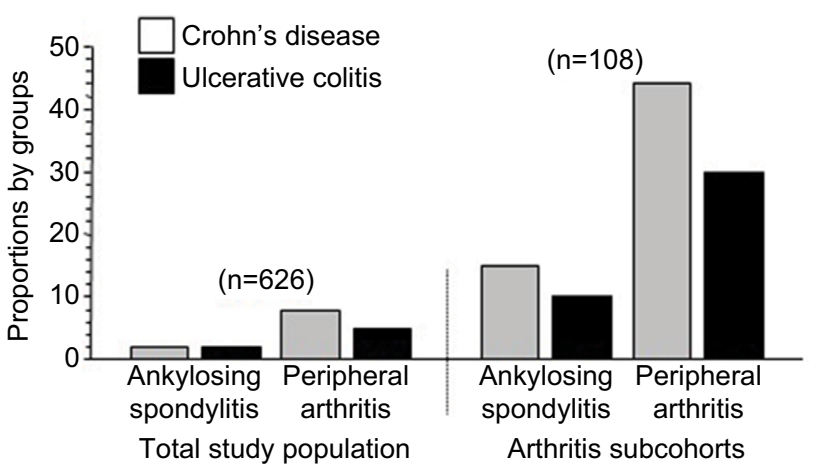

Figure $\mathbf{2}$ The distribution of the four groups of joint pain by IBD subtype among the VA cohort study population.

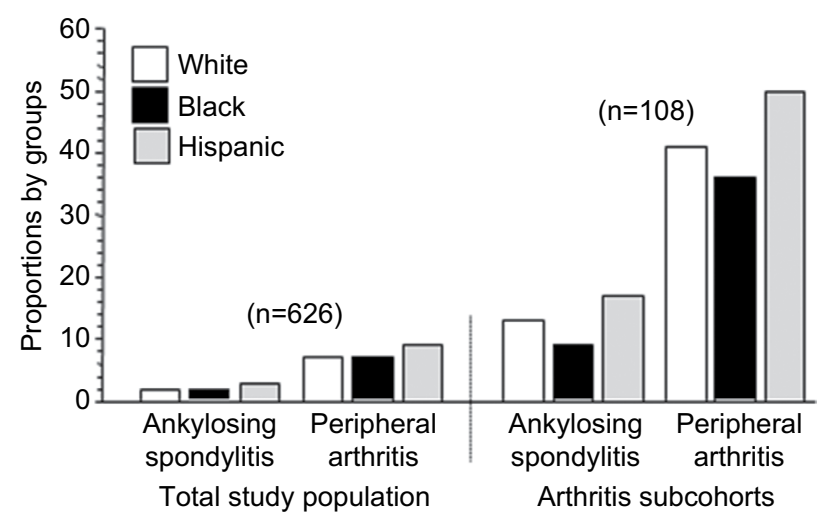

Figure 3 Race/ethnicity-specific distribution of the four groups of joint pain among the VA cohort study population. with joint pain, $68 \%$ had any type of joint pain after the initial diagnosis of IBD, ranging from 1 to 17 years (mean \pm SD $9.3 \pm 4.5$ ), $25 \%$ within the same year as the first IBD encounter, and only $7 \%$ had any type of joint pain before the initial diagnosis of IBD, ranging from 1 to 11 years (mean \pm SD $5.6 \pm 6.1$. The same pattern was consistent within each group of joint pain (Table 1).

\section{Discussion}

The main strength of this study is its population-based design and availability of clinical information from the VA data sets. Our study found the overall prevalence of all types of joint pains to be $17 \%$. The prevalence of inflammatory peripheral arthritis was $7.3 \%$, which is slightly higher among $\mathrm{CD}$ than UC patients. This finding is consistent with a previously reported study from Oxford, England, that reported the frequency of peripheral arthritis at $3.6 \%$ in patients with UC and $6 \%$ in patients with $\mathrm{CD}^{8}{ }^{8}$ On the other hand, our findings were in contrast with two retrospective studies from Europe that reported conflicting results to each other on the prevalence of peripheral arthritis between CD and UC patients. The first study from Italy reported that the prevalence of peripheral arthritis among UC patients is much higher than in CD patients (6.1\% vs $1.7 \%)$, respectively, ${ }^{13}$ whereas the second one from Switzerland reported a higher prevalence of arthritis among CD, than in UC, patients. ${ }^{14}$ The inconsistency between our results and those from previous studies could be attributed to study design, because our study was based on review of medical records, whereas the other two studies obtained their data through physician and patient questionnaires.

The frequency of AS in our current study was significantly lower than the prevalence of inflammatory peripheral arthritis and did not differ between $\mathrm{CD}$ and UC patients. This finding is in accordance with two prior studies from Olmsted County that independently examined two cohorts of $\mathrm{CD}$ and

Table I Start of joint symptoms relative to IBD diagnosis in the 108 patients

\begin{tabular}{|c|c|c|c|c|c|}
\hline Variables & $\begin{array}{l}\text { All with IBD and joint } \\
\text { symptoms }\end{array}$ & $\begin{array}{l}\text { Ankylosing } \\
\text { spondylitis }\end{array}$ & $\begin{array}{l}\text { Inflammatory } \\
\text { peripheral arthritis }\end{array}$ & $\begin{array}{l}\text { Non-inflammatory } \\
\text { back pain }\end{array}$ & $\begin{array}{l}\text { Non-inflammatory } \\
\text { peripheral arthritis }\end{array}$ \\
\hline Number of patients & 108 & 13 & 46 & 35 & 14 \\
\hline $\begin{array}{l}\text { IBD diagnosis prior to joint } \\
\text { symptoms (\%) }\end{array}$ & 68 & 62 & 65 & 72 & 86 \\
\hline Range/years & $1-17$ years & $4-13$ & $2-17$ & $1.5-17$ & $4-16$ \\
\hline Mean (SD) & $9.3( \pm 4.5)$ & $8.5( \pm 3.3)$ & $9.5( \pm 4.5)$ & $9.2( \pm 4.3)$ & $10.1( \pm 4.9)$ \\
\hline Same year $\%$ & 25 & 31 & 24 & 28 & 7 \\
\hline $\begin{array}{l}\text { IBD diagnosis after onset of } \\
\text { joint symptoms (\%) }\end{array}$ & 7 & 7 & II & & 7 \\
\hline Range in years & $||-||$. & I patient & $I . I-4$ & NA & I patient \\
\hline Mean (SD) & $5.6(6.1)$ & & $2.5(1.3)$ & & \\
\hline
\end{tabular}

Abbreviations: IBD, inflammatory bowel disease; NA, not applicable. 
UC patients and reported that the increase of the cumulative incidence of AS was similar for both CD and UC patients. ${ }^{15,16}$ It is important to estimate and compare the prevalence of both AS and inflammatory peripheral arthritis among IBD patients to understand the associations between these diseases for better management and treatment of both conditions.

Our results did not find a difference of any type of joint pain based on race and/or ethnicity. Previous studies have examined phenotypic and outcome differences by race and ethnicity in IBD, but with conflicting results. ${ }^{17-19}$ A large population-based study that examined IBD characteristics among African Americans, Hispanics, and non-Hispanic White reported that there are racial differences in IBD EIMs, ${ }^{20}$ whereas another study published that African Americans have similar variety and frequency of EIMs compared to Caucasians. ${ }^{21}$ Further studies comparing the prevalence and characteristics of the EIMs between Caucasian and non-Caucasian populations may provide insight into the impact of genetic variations on the clinical course of both IBD and EIMs.

Of interest, our study revealed that AS, inflammatory peripheral arthritis, and non-inflammatory joint complaints are most often diagnosed after the initial diagnosis of IBD and implies that IBD may share environmental triggers, genetic susceptibilities, or alterations in immune homeostasis with inflammatory arthritis. It is important to recognize IBD comorbidities to promptly evaluate, diagnose, and treat or refer to other specialists. Early recognition and treatment of IBD-associated manifestation are crucial in preventing major morbidity.

The ICD-9 codes are useful in clinical research and we have previously validated the ICD-9 code for identifying patients with IBD in the Veterans Affairs Health Care System. ${ }^{22}$ However, a major shortcoming of the current study is that we relied on ICD-9 coding for identifying only IBD as there are no validated ICD-9 code case-finding algorithms for AS and back pain among an IBD population. However, we have performed detailed chart reviews for each of the studied cases to confirm cases. Our study population predominantly comprised Caucasian males and, therefore, our findings may not be generalizable to female populations or non-Caucasians. However, our population is more racially/ethnically diverse than many other reported IBD populations.

\section{Conclusion}

Our study demonstrates that both inflammatory and noninflammatory joint complaints are common among IBD patients and are usually diagnosed after the initial diagnosis of IBD. No differences in the prevalence of AS or inflammatory peripheral arthritis were observed based on IBD type, age, or race. Recognition and clear understanding of these results will have important implications for management and treatment of both IBD and related joint complaints.

\section{Acknowledgments}

This study was supported UCB Pharm and supported in part with resources at the VA HSR\&D Center for Innovations in Quality, Effectiveness and Safety (\#CIN 13-413), at the Michael E. DeBakey VA Medical Center, Houston, TX, USA. The content is solely the responsibility of the authors and does not necessarily represent the official views of the Department of Veterans Affairs.

\section{Author contributions}

Hoda M Malaty was involved in planning, conducting the study, collecting and interpreting the data, drafting the manuscript, and has approved the final draft submitted.

Jason K Hou was involved in planning, collecting and/ or interpreting data, and drafting the manuscript, and has approved the final draft submitted.

Grace Lo was involved in planning and interpreting data, drafting the manuscript, and has approved the final draft submitted.

\section{Disclosure}

The authors report no conflicts of interest in this work.

\section{References}

1. Bourikas LA, Papadakis KA. Musculoskeletal manifestations of inflammatory bowel disease. Inflamm Bowel Dis. 2009;15(12): 1915-1924.

2. Ardizzone S, Puttini PS, Cassinotti A, Porro GB. Extraintestinal manifestations of inflammatory bowel disease. Dig Liver Dis. 2008;40(Suppl 2):S253-S259.

3. Bernstein CN, Blanchard JF, Rawsthorne P, Yu N. The prevalence of extraintestinal diseases in inflammatory bowel disease: a populationbased study. Am J Gastroenterol. 2001;96(4):1116-1122.

4. Rudwaleit M, van der Heijde D, Landewé R, et al. The development of Assessment of SpondyloArthritis International Society classification criteria for axial spondyloarthritis (part II): validation and final selection. Ann Rheum Dis. 2009;68(6):777-783.

5. Dean LE, Macfarlane GJ, Jones GT. Differences in the prevalence of ankylosing spondylitis in primary and secondary care: only one-third of patients are managed in rheumatology. Rheumatology (Oxford). 2016;55(10):1820-1825.

6. Gionchetti P, Calabrese C, Rizzello F. Inflammatory bowel diseases and spondyloarthropathies. J Rheumatol Suppl. 2015;93:21-23.

7. van Erp SJ, Brakenhoff LK, van Gaalen FA, et al. Classifying back pain and peripheral joint complaints in inflammatory bowel disease patients: a prospective longitudinal follow-up study. J Crohn's Colitis. 2016;10(2):166-175. 
8. Orchard TR, Wordsworth BP, Jewell DP. Peripheral arthropathies in inflammatory bowel disease: their articular distribution and natural history. Gut. 1998;42(3):387-391.

9. Rodriguez VE, Costas PJ, Vazquez M, et al. Prevalence of spondyloarthropathy in Puerto Rican patients with inflammatory bowel disease. Ethn Dis. 2008;18(2 Suppl 2):S2-225-229.

10. Palm O, Moum B, Ongre A, Gran JT. Prevalence of ankylosing spondylitis and other spondyloarthropathies among patients with inflammatory bowel disease: a population study (the IBSEN study). J Rheumatol. 2002;29(3):511-515.

11. de Vlam K, Mielants H, Cuvelier C, De Keyser F, Veys EM, De Vos M. Spondyloarthropathy is underestimated in inflammatory bowel disease: prevalence and HLA association. J Rheumatol. 2000;27(12):2860-2865.

12. Lanna CC, Ferrari Mde L, Rocha SL, Nascimento E, de Carvalho MA, da Cunha AS. A cross-sectional study of 130 Brazilian patients with Crohn's disease and ulcerative colitis: analysis of articular and ophthalmologic manifestations. Clin Rheumatol. 2008;27(4): 503-509.

13. Salvarani C, Vlachonikolis IG, van der Heijde DM, et al; European Collaborative IBD Study Group. Musculoskeletal manifestations in a population-based cohort of inflammatory bowel disease patients. Scand J Gastroenterol. 2001;36(12):1307-1313.

14. Vavricka SR, Brun L, Ballabeni P, et al. Frequency and risk factors for extraintestinal manifestations in the Swiss inflammatory bowel disease cohort. Am J Gastroenterol. 2011;106(1):110-119.
15. Shivashankar R, Loftus EV Jr, Tremaine WJ, et al. Incidence of spondyloarthropathy in patients with Crohn's disease: a population-based study. J Rheumatol. 2012;39(11):2148-2152.

16. Shivashankar R, Loftus EV Jr, Tremaine WJ, Harmsen WS, Zinsmeister AR, Matteson EL. Incidence of spondyloarthropathy in patients with ulcerative colitis: a population-based study. J Rheumatol. 2013;40(7):1153-1157.

17. Sofia MA, Rubin DT, Hou N, Pekow J. Clinical presentation and disease course of inflammatory bowel disease differs by race in a large tertiary care hospital. Dig Dis Sci. 2014;59(9):2228-2235.

18. Sewell JL, Inadomi JM, Yee HF Jr. Race and inflammatory bowel disease in an urban healthcare system. Dig Dis Sci. 2010;55(12):3479-3487.

19. Lin KK, Sewell JL. The effects of race and socioeconomic status on immunomodulator and anti-tumor necrosis factor use among ambulatory patients with inflammatory bowel disease in the United States. $\mathrm{Am}$ J Gastroenterol. 2013;108(12):1824-1830.

20. Nguyen GC, Torres EA, Regueiro M, et al. Inflammatory bowel disease characteristics among African Americans, Hispanics, and non-Hispanic Whites: characterization of a large North American cohort. Am J Gastroenterol. 2006;101(5):1012-1023.

21. Mahid SS, Mulhall AM, Gholson RD, Eichenberger MR, Galandiuk S. Inflammatory bowel disease and African Americans: a systematic review. Inflamm Bowel Dis. 2008;14(7):960-967.

22. Hou JK, Tan M, Stidham RW, et al. Accuracy of diagnostic codes for identifying patients with ulcerative colitis and Crohn's disease in the Veterans Affairs Health Care System. Dig Dis Sci. 2014;59(10):2406-2410.

\section{Clinical and Experimental Gastroenterology}

\section{Publish your work in this journal}

Clinical and Experimental Gastroenterology is an international, peerreviewed, open access, online journal publishing original research, reports, editorials, reviews and commentaries on all aspects of gastroenterology in the clinic and laboratory. This journal is included on PubMed. The manuscript management system is completely online

\section{Dovepress}

and includes a very quick and fair peer-review system, which is all easy to use. Visit http://www.dovepress.com/testimonials.php to read real quotes from published authors. 